\title{
Association of Post-extubation Dysphagia With Tongue Weakness and Somatosensory Disturbance in Non-neurologic Critically Ill Patients
}

\author{
Hee Seon Park, MD, Jung Hoi Koo, MD, Sun Hong Song, MD
}

Department of Rehabilitation Medicine, Gangneung Asan Hospital, University of Ulsan College of Medicine, Gangneung, Korea

\begin{abstract}
Objective To prospectively assess the association between impoverished sensorimotor integration of the tongue and lips and post-extubation dysphagia (PED).

Methods This cross-sectional study included non-neurologic critically ill adult patients who required endotracheal intubation and underwent videofluoroscopic swallowing study (VFSS) between October and December 2016. Participants underwent evaluation for tongue and lip performance, and oral somatosensory function. Demographic and clinical data were retrieved from medical records.

Results Nineteen patients without a definite cause of dysphagia were divided into the non-dysphagia $(n=6)$ and the PED ( $n=13)$ groups based on VFSS findings. Patients with PED exhibited greater mean duration of intubation (11.85 \pm 3.72 days) and length of stay in the intensive care unit (LOS-ICU; 13.69 \pm 3.40 days) than those without PED (6.83 \pm 5.12 days and $9.50 \pm 5.96$ days; $p=0.02$ and $p=0.04$, respectively). The PED group exhibited greater incidence of pneumonia, higher videofluoroscopy swallow study dysphagia scale score, higher oral transit time, and lower tongue power and endurance and lip strength than the non-dysphagia groups. The differences in two-point discrimination and sensations of light touch and taste among the two groups were insignificant. Patients intubated for more than 7 days exhibited lower maximal tongue power and tongue endurance than those intubated for less than a week.

Conclusion Duration of endotracheal intubation, LOS-ICU, and oromotor degradation were associated with PED development. Oromotor degradation was associated with the severity of dysphagia. Bedside oral performance evaluation might help identify patients who might experience post-extubation swallowing difficulty.
\end{abstract}

Keywords Aspiration, Critical illness, Deglutition disorders, Fluoroscopy, Intratracheal intubation

Received February 3, 2017; Accepted April 4, 2017

Corresponding author: Jung Hoi Koo

Department of Rehabilitation Medicine, Gangneung Asan Hospital, 38 Bangdong-gil, Gangneung 25440, Korea. Tel: +82-33-610-4951, Fax: +82-33-6104960, E-mail: mdjhkoo@gnah.co.kr

ORCID: Hee Seon Park (http://orcid.org/0000-0003-1766-4180); Jung Hoi Koo (http://orcid.org/0000-0002-4179-3217); Sun Hong Song (http://orcid. org/0000-0002-0728-8997).

(c) This is an open-access article distributed under the terms of the Creative Commons Attribution Non-Commercial License (http://creativecommons.org/ licenses/by-nc/4.0) which permits unrestricted noncommercial use, distribution, and reproduction in any medium, provided the original work is properly cited. Copyright ( 2017 by Korean Academy of Rehabilitation Medicine 


\section{INTRODUCTION}

Dysphagia is a common complication following neurologic conditions, such as stroke, traumatic brain injury, and Parkinson disease. It can also occur after surgical procedures, such as cervical spine surgery, pharyngeal resection, laryngectomy, hemiglossectomy, which affect swallowing-related structures. However, unrelated to these structures, some patients without neurologic illnesses can also develop dysphagia after endotracheal intubation.

A systematic review reported that prolonged endotracheal intubation causes dysphagia and severe complications like aspiration pneumonia [1]. In a recent study, the frequency of post-extubational supraglottic and infraglottic aspiration in non-neurologic critically ill patients was reported to be $59 \%$, and the severity of dysphagia was related with the duration of intubation [2].

The tongue plays a major role in the formation, placement, and manipulation of food bolus, propulsion of bolus to the pharyngeal cavity, and downward movement of bolus by coordinated motion during pharyngeal reflex [3]. In patients who have suffered stroke, tongue weakness is associated with reduced maximal swallowing pressure, which results in penetration and aspiration [4]. Weakness of vocal-fold motion and diminished pharyngeal sensation are well-known factors for post-extubational aspiration in ventilated patients. Additionally, tongue weakness due to sarcopenia and diminished somatosensory function of the tongue could also be a factor for post-extubation dysphagia (PED) $[5,6]$.

Videofluoroscopic swallowing study (VFSS) is an objective method to quantify swallowing difficulty in patients with dysphagia. However, it is not routinely performed for extubated patients with non-neurologic critical illness. There is no standard protocol for the objective evaluation of dysphagia and optimization of diet in extubated patients. Additionally, VFSS cannot evaluate tongue and lip function.

Recently, the Iowa Oral Performance Instrument (IOPI; IOPI Medical LLC, Redmond, WA, USA) was introduced for assessment of tongue and lip function. Until now, only a few studies have reported that diminished tongue pressure measured by IOPI appears to be closely related to the diminished oral phase swallowing function in patients after stroke [7]. In the present study, the IOPI and VFSS were together used to evaluate tongue and lip strength, and to determine whether tongue and lip weakness correlates with PED.

The aim of this study was to determine the incidence of PED confirmed by videofluoroscopy and the association of PED with tongue strength and endurance, lip strength, and somatosensory deficits of the tongue in non-neurologic critically ill patients.

\section{MATERIALS AND METHODS}

\section{Subjects}

Between October and December 2016, 209 patients were referred to our department for evaluation of dysphagia. Thirty-nine patients aged 18-90 years admitted to the intensive care unit (ICU) were selected for this study. Of the 39 patients, 36 had received oral endotracheal intubation for at least 48 hours. Patients were excluded if they had (1) a history of neurologic diseases (e.g., stroke, Parkinsonism, or traumatic brain injury), (2) low Glasgow Coma Scale scores, (3) an inability to respond to questions, (4) received tracheostomy, (5) head and neck cancer or history of head or neck surgery, or (6) pre-existing dysphagia. Pre-existing dysphagia was determined by directly querying the subjects and by performing chart review to determine whether they had a history of pneumonia, coughing upon consumption of liquids, globus sensation, food sticking, weight loss, or diet modification before hospital admission. We finally selected 19 patients (14 males and 5 females; mean age, $67.42 \pm 13.17$ years) who met the exclusion criteria.

\section{Methods \\ IOPI analysis}

All participants underwent motorsensory evaluation 4-14 days post-extubation. Tongue strength and endurance were measured using the IOPI, which consists of an air-filled plastic bulb connected to the measurement device through plastic tubing. Participants were instructed to push the bulb against the hard palate just behind the upper alveolar ridge using their tongue, with as much effort as possible. Maximal tongue pressure was measured by asking the participants to push their tongue out with as much effort as possible; a single well-trained clinician recorded the maximal pressure from the digital readout of the IOPI. Tongue endurance was defined as 
the duration for which patient could maintain a pressure equivalent to $50 \%$ of their maximal tongue pressure, while keeping the green light on. The pressure required to turn the green light on was set at $50 \%$ of the maximum tongue pressure in each case. Lip strength was measured by placing the IOPI bulb between the lips and having the participants purse their lips as hard as possible. All of the measurements were repeated three times, with 10-15 seconds of rest in between. The mean value of each measurement was considered for further analysis.

\section{Sensory function}

For oral somatosensory function analysis, the tongue was assessed for sensations of light touch and taste, and two-point discrimination by a single well-trained clinician, with the participants blindfolded. Sensation of light touch was evaluated over three trials with a thin wisp of cotton, for which participants responded with 'yes' (perceived touch) or 'no' (did not perceive touch). To ensure that participants were not guessing, a sham trial was conducted in which a thin wisp of cotton was placed near but not in contact with the tongue. Sensation of taste was evaluated using four different solutions: salty (sodium chloride; $30 \mathrm{mg}$ tablet salt in $1 \mathrm{~L}$ water), sweet (sucrose; $60 \mathrm{mg}$ refined sugar in $1 \mathrm{~L}$ water), sour (citric acid; $60 \mathrm{~mL}$ commercial lemon juice in $1 \mathrm{~L}$ water), and neutral (distilled water) solutions. Participants were blindfolded, and $1 \mathrm{~mL}$ of each solution was applied to the center of the tongue in random order. Participants were coached to respond 'salty', 'sweet', 'sour', or 'just water'. Between each trial, subjects were provided $30 \mathrm{~mL}$ distilled water to clear residual material. Two-point discrimination was evaluated using 2, 3, 4, 5, 6, and $7 \mathrm{~mm}$ paperclips. Participants were coached to indicate perception of paperclips on the tongue by raising one or two fingers. To ensure accuracy of measurement, tests were administered in a random order.

\section{VFSS analysis}

Fluoroscopic analysis was performed in the lateral view by an experienced clinician and a radiographer trained in videofluoroscopy, under the supervision of a rehabilitation specialist. Although, Scheel et al. [8] found no association between the timing of assessment and PED, we performed the VFSS on days 1-7 post-extubation. Each subject performed a total of nine swallows of 3, 5, and 8 $\mathrm{mL}$ each of thin and thick liquids (Solotop Suspensions
70 and 140, respectively; Taejoon Pharm, Seoul, Korea) via a catheter-tip syringe, and $3 \mathrm{~mL}$ each of rice porridge, chopped fruit, and boiled egg containing barium solution (Solotop Powder For Suspension; Taejoon Pharm) via a spoon. PED was defined as the difficulty or inability to effectively and safely transfer food and liquid from the mouth to the stomach after extubation. Aspiration was defined as passage of materials through the vocal folds. Laryngeal penetration was defined as passage of materials into the larynx but not through the vocal folds. Severity of dysphagia was quantified using a 100-point VFSS dysphagia scale (VDS), which is applicable to patients with dysphagia due to numerous possible etiologies [9]. The VDS consisted of subscales of lip closure, bolus formation, mastication, apraxia, tongue-to-palate contact, premature bolus loss, oral transit time (OTT), triggering of pharyngeal swallow, vallecular residue, laryngeal elevation, pyriform sinus residue, coating on the pharyngeal wall, pharyngeal transit time (PTT), and aspiration. While OTT was scored 0 or 3 (if it exceeded 1.5 seconds) and PTT was scored 0 or 6 (if it exceeded 1.0 seconds).

\section{Other measures}

To investigate the risk factors for PED, data regarding the following variables of interest were retrieved from medical records. These included duration of endotracheal intubation, demographic information (age and sex), diagnosis leading to ICU admission, length of stay in the ICU (LOS-ICU), and medication (opiates, sedatives, and neuromuscular blockers). Diagnosis leading to ICU admission was categorized according to etiology as follows: respiratory, cardiac, cancer, intoxication, motor vehicle accident, sepsis, surgical, and miscellaneous etiologies.

Aspiration pneumonia was diagnosed according to the following criteria: history of suspected aspiration (e.g., choking during a meal or cough), fever, elevated white blood cell count, and C-reactive protein levels, and abnormal chest radiography or computed tomography findings.

The study design was prospective and cross-sectional in nature. All of the study protocols were approved by the Institutional Review Board of Gangneung Asan Hospital (IRB No. 2016-09-005), and informed patient consent was obtained.

\section{Statistical analyses}

Statistical analyses were performed using SPSS program 
ver. 22.0 for Windows (IBM SPSS Inc., Armonk, NY, USA). Values of $\mathrm{p}<0.05$ were considered significant. Comparison of sex, age, incidence of pneumonia, LOS-ICU, duration of endotracheal intubation, and VDS scores among two groups of patients categorized according to the presence of penetration or aspiration was performed by the Mann-Whitney U-test. Categorical variables of sex, diagnosis leading to ICU admission, incidence of pneumonia, OTT, and PTT were reported as frequency and proportion and descriptively analyzed by Fisher exact test.

\section{RESULTS}

Demographic data of age and sex showed no statistical differences. The most common disease category for admission to the ICU was respiratory diseases (Table 1), which included one case each of chronic necrotizing pulmonary aspergillosis, chronic obstructive pulmonary disease, pulmonary thromboembolism, and acute respiratory distress syndrome, and five cases of pneumonia. The mean LOS-ICU and duration of endotracheal intubation were $10.26 \pm 4.71$ days and $12.37 \pm 4.65$ days, respectively (Table 2).

We defined PED as presentation of aspiration or penetration on VFSS findings. The incidence of PED confirmed by videofluoroscopy was $68.42 \%$. On the basis of VFSS findings, patients were divided into the nondysphagic group $(n=6)$ and the dysphagic (supraglottic penetration and aspiration; $n=13$ ) group. The mean duration of intubation and LOC-ICU in patients with PED (11.85 \pm 3.72 days and $13.69 \pm 3.40$ days, respectively) were longer compared to those in patients without PED

Table 1. Comparison of demographic and clinical characteristics of patients with and without PED

\begin{tabular}{lcccc}
\hline & $\begin{array}{c}\text { Total } \\
(\mathbf{n}=\mathbf{1 9})\end{array}$ & $\begin{array}{c}\text { Non-dysphagic group } \\
(\mathbf{n = 6})\end{array}$ & $\begin{array}{c}\text { PED group } \\
(\mathbf{n}=\mathbf{1 3})\end{array}$ & p-value \\
\hline Age (yr) & $67.42 \pm 13.17$ & $67.33 \pm 9.56$ & $67.46 \pm 14.90$ & 0.826 \\
Male & $14(73.7)$ & $3(50.0)$ & $11(84.6)$ & 0.262 \\
\hline ICU diagnosis & & & \\
Respiratory & $9(47.4)$ & $4(21.1)$ & $5(26.3)$ & \\
Sepsis (non-respiratory) & $3(15.8)$ & $0(0)$ & $3(15.8)$ & \\
Endocrinologic & $2(10.5)$ & $1(5.3)$ & $1(5.3)$ & \\
Renal & $1(5.3)$ & $0(0)$ & $1(5.3)$ & \\
\hline Intoxication & $1(5.3)$ & $0(0)$ & $1(5.3)$ & \\
\hline Others & $3(15.8)$ & $1(5.3)$ & $2(10.5)$ & \\
\hline
\end{tabular}

Values are presented as mean \pm standard deviation or number of subjects (\%).

PED, post-extubation dysphagia; ICU, intensive care unit.

Table 2. Association of PED with duration of intubation and LOS-ICU

\begin{tabular}{lcccc}
\hline & $\begin{array}{c}\text { Total } \\
(\mathbf{n}=\mathbf{1 9})\end{array}$ & $\begin{array}{c}\text { Non-dysphagic } \\
\text { group }(\mathbf{n}=\mathbf{6})\end{array}$ & $\begin{array}{c}\text { PED group } \\
(\mathbf{n = 1 3})\end{array}$ & p-value \\
\hline Duration of intubation (day) & $10.26 \pm 4.71$ & $6.83 \pm 5.12$ & $11.85 \pm 3.72$ & $0.016^{*}$ \\
\hline LOS-ICU (day) & $12.37 \pm 4.65$ & $9.50 \pm 5.96$ & $13.69 \pm 3.40$ & $0.039^{*}$ \\
\hline Pneumonia affected & $12(63.2)$ & $1(16.7)$ & $11(84.6)$ & $0.010^{*}$ \\
VDS & $18.42 \pm 12.93$ & $4.75 \pm 7.40$ & $25.19 \pm 9.32$ & $0.002^{*}$ \\
Oral phase & $2.63 \pm 2.89$ & $2.17 \pm 3.36$ & $2.85 \pm 2.76$ & 0.641 \\
OTT & $7(36.8)$ & $0(0)$ & $7(53.8)$ & $0.044^{*}$ \\
\hline PTT & $2(10.5)$ & $0(0)$ & $2(15.4)$ & 1.000 \\
\hline
\end{tabular}

Values are presented as mean \pm standard deviation or number (\%).

PED, post-extubation dysphagia; LOS-ICU, length of stay in the intensive care unit; VDS, videofluoroscopy swallow study dysphagia scale; OTT, oral transit time; PTT, pharyngeal transit time.

${ }^{*} \mathrm{p}<0.05$ by the Mann-Whitney U-test. 
(6.83 \pm 5.12 days and $9.50 \pm 5.96$ days, respectively; $\mathrm{p}=0.02$ and $\mathrm{p}=0.04$, respectively) (Table 2 ).

The incidence of pneumonia in the non-dysphagic and dysphagic group was $16.7 \%$, and $84.6 \%$ respectively, which indicated that PED and pneumonia were positively correlated. The mean VDS scores of the non-dysphagia, PED groups were $4.75 \pm 7.40$ and $25.19 \pm 9.32$, respectively $(\mathrm{p}=0.002)$. The oral phase scored 40-points on the VDS involving lip closure, bolus formation, mastication, apraxia, tongue-to-palate contact, premature bolus loss, and OTT. There were no statistically significant differences in PTT and oral phase scores. However, OTT was significantly prolonged in the PED group.

Values of maximal tongue power in the non-dysphagia and PED groups were $36.00 \pm 4.43 \mathrm{kPa}$ and $13.77 \pm 7.41 \mathrm{kPa}$, respectively (Table 3 ). Severity of PED was correlated with lower maximal tongue power $(\mathrm{p}=0.001)$, tongue en- durance $(\mathrm{p}=0.001)$, and lip strength $(\mathrm{p}=0.001)$. No correlation was observed between oral sensory changes (twopoint discrimination and sensation of light touch and taste) and severity of dysphagia (Table 3 ).

Tongue power and endurance in patients who were intubated for over a week $(17.15 \pm 7.93 \mathrm{kPa}$ and $13.92 \pm 5.50$ $\mathrm{kPa}$, respectively) were lower compared to those in patients who were intubated for less than a week $(32.83 \pm 8.75$ $\mathrm{kPa}$ and $23.50 \pm 6.89 \mathrm{kPa}$, respectively; $\mathrm{p}=0.004$ and $\mathrm{p}=0.02$, respectively) (Table 4). However, duration of intubation was not associated with lip power, two-point discrimination, or sensation of light touch or taste.

\section{DISCUSSION}

The findings of this prospective, cross-sectional study of non-neurologic critically ill patients who received en-

Table 3. Association of PED with tongue and lip weakness and somatosensory disturbance

\begin{tabular}{|c|c|c|c|c|}
\hline & $\begin{array}{c}\text { Total } \\
(n=19)\end{array}$ & $\begin{array}{l}\text { Non-dysphagic } \\
\text { group }(n=6)\end{array}$ & $\begin{array}{c}\text { PED group } \\
(\mathrm{n}=13)\end{array}$ & p-value \\
\hline \multicolumn{5}{|l|}{ Tongue and lip weakness } \\
\hline Tongue maximal power $(\mathrm{kPa})$ & $22.11 \pm 10.92$ & $36.00 \pm 4.43$ & $13.77 \pm 7.41$ & $0.001^{*}$ \\
\hline Tongue endurance (s) & $16.95 \pm 7.37$ & $25.67 \pm 4.59$ & $11.08 \pm 5.47$ & $0.001^{*}$ \\
\hline Lip power $(\mathrm{kPa})$ & $17.84 \pm 8.91$ & $28.17 \pm 2.99$ & $12.38 \pm 6.47$ & $0.001^{*}$ \\
\hline \multicolumn{5}{|l|}{ Somatosensory disturbance } \\
\hline Two-point discrimination (mm) & $4.42 \pm 1.68$ & $4.00 \pm 1.90$ & $4.62 \pm 1.61$ & 0.389 \\
\hline Light touch & $2.16 \pm 0.96$ & $2.50 \pm 0.84$ & $2.00 \pm 1.00$ & 0.279 \\
\hline Taste & $3.68 \pm 0.82$ & $3.67 \pm 0.82$ & $3.69 \pm 0.85$ & 0.945 \\
\hline
\end{tabular}

Values are presented as mean \pm standard deviation.

PED, post-extubation dysphagia.

${ }^{*} \mathrm{p}<0.05$ by the Mann-Whitney U-test.

Table 4. Association of duration of intubation with tongue weakness and somatosensory disturbance

\begin{tabular}{|c|c|c|c|}
\hline & $\begin{array}{l}\text { Intubation duration } \\
\text { less than a week }\end{array}$ & $\begin{array}{c}\text { Intubation duration } \\
\text { over a week }\end{array}$ & p-value \\
\hline \multicolumn{4}{|l|}{ Tongue and lip weakness } \\
\hline Tongue maximal power $(\mathrm{kPa})$ & $32.83 \pm 8.75$ & $17.15 \pm 7.93$ & $0.004^{*}$ \\
\hline Tongue endurance $(\mathrm{kPa})$ & $23.50 \pm 6.89$ & $13.92 \pm 5.50$ & $0.017^{*}$ \\
\hline Lip power $(\mathrm{kPa})$ & $24.33 \pm 8.96$ & $14.85 \pm 7.40$ & 0.065 \\
\hline \multicolumn{4}{|l|}{ Somatosensory disturbance } \\
\hline Two-point discrimination (mm) & $3.67 \pm 1.86$ & $4.77 \pm 1.54$ & 0.174 \\
\hline Light touch & $2.50 \pm 0.84$ & $2.00 \pm 1.00$ & 0.279 \\
\hline Taste & $3.67 \pm 0.82$ & $3.69 \pm 0.85$ & 0.945 \\
\hline
\end{tabular}

Values are presented as mean \pm standard deviation.

${ }^{*} \mathrm{p}<0.05$ by the Mann-Whitney U-test. 
dotracheal intubation demonstrate that the duration of intubation might be associated with the development of dysphagia after extubation. This result is consistent with that of a previous study [10]. The duration of endotracheal intubation might be positively correlated with the severity of dysphagia. Although several studies have employed the VFSS for dysphagia, few have included postextubational patients. A systematic review of 1,489 studies on PED [1] identified only three studies [11-13] that employed VFSS for confirming dysphagia. However, since all of these studies had employed VFSS only in patients who failed the bedside swallowing test or had exhibited clinical signs of aspiration, they might have excluded some patients with silent aspiration. Furthermore, Ferraris et al. [12] enrolled patients with prior transient ischemic attack or stroke. Therefore, it has been challenging to determine whether PED results from intubation. The strength of the present study is that patients with neurologic disorders were excluded to minimize confounding factors related to dysphagia; additionally, all subjects enrolled in this study underwent the VFSS for objective confirmation of dysphagia.

A previous study involving healthy male and female subjects reported maximal isometric tongue strength ranging from $19.25 \pm 18.64 \mathrm{kPa}$ to $73.33 \pm 12.03 \mathrm{kPa}$ [14]. However, the present study sample exhibited lower mean maximal isometric tongue strength; $22.11 \pm 10.92 \mathrm{kPa}$. It might have been because the present study sample included only critically ill patients.

Another previous study reported maximal isometric tongue strength values of $63.9 \pm 15.2 \mathrm{kPa}, 61.5 \pm 13.0 \mathrm{kPa}$, and $54.5 \pm 11.1 \mathrm{kPa}$ in healthy subjects with ages of 20-39, 40-59, and 60-79 years, respectively [15]. These findings were attributed to age-related reduction in muscle mass [16]. Decreased tongue pressure has been reported to be associated with sarcopenia [5]. Therefore, prolonged intubation might result in reduction of tongue muscle mass and maximal tongue power.

In a previous study, mean tongue endurance in a healthy population ranged from $15.72 \pm 5.86$ to $37.85 \pm 23.55 \mathrm{sec}-$ onds, regardless of age [14]. These values are greater compared to those observed in the present study; $16.95 \pm 7.37$ seconds, where duration of intubation was found to be negatively correlated with tongue endurance.

Oral motor exercises can help improve motor functions of the tongue. In a previous study, peak isometric, and swallowing pressures were increased after 8 weeks of lingual muscle exercise in healthy elderly subjects suspected of sarcopenia in the bulbar innervated tongue musculature, although there was no improvement in the extent of penetration/aspiration [4]. However, these results were obtained in healthy elderly subjects without swallowing difficulties. This indicates that, in subjects with sarcopenia due to prolonged intubation, lingual muscle exercise might increase tongue strength and subsequently alleviate PED as well as related complications such as pneumonia, malnutrition, and dehydration.

A previous study reported mean lip strength values of $33.8 \pm 15.1 \mathrm{kPa}$ and $22.4 \pm 7.5 \mathrm{kPa}$, respectively, in healthy male and female subjects 18-89 years of age, with no agespecific differences [17]. The mean lip strength observed in the present study $(17.84 \pm 8.91 \mathrm{kPa})$ was lower compared to that in the previous study. Weakness of labial muscles renders lip closure difficult and causes drooling, loss of food from the mouth, reduced chewing rate and efficiency, and reduced straw suction [18]. Participants in the present study exhibited difficulties in lip closure, drooling, and loss of food from the mouth in the VFSS. Thus, loss of maximal lip compression strength might be one of the factors for dysphagia in extubated patients.

In normal swallowing, tactile receptors in the oropharynx transmit signals to the trigeminal sensory nuclei via the trigeminal nerve and afferent sensory nerve fibers [19]. Taste receptors in the oropharynx transmit signals via the chorda tympani to the nucleus tractus solitarius and then to the primary sensory cortex of the brain [20]. These oral-sensory inputs result in the activation of swallowing-related regions including the primary motor cortex, cingulate cortex, putamen, and insula [19-21].

Taste recognition in healthy subjects is not $100 \%$ accurate. In a previous study, accuracies of participant responses were reported to be $90 \%$ for neutral, $90 \%$ for salty, $\mathbf{9 2 . 5 \%}$ for sweet, and $\mathbf{8 0 \%}$ for sour tastes [22]. Presently, there were no differences in taste recognition among the three groups, which indicated that there was no association between intubation and taste recognition, and that the sense of taste might be spared after prolonged intubation.

A previous study reported two-point discrimination values of $2.1 \pm 0.3 \mathrm{~mm}$ in healthy control subjects and $3.2 \pm 1.6$ $\mathrm{mm}$ in extubated subjects 4 hours after extubation [6]. In contrast, the mean two-point discrimination value in the 
present study was $4.42 \pm 1.68 \mathrm{~mm}$, which indicates poorer discrimination among the present study sample. However, there were no differences in two-point discrimination among the three groups.

Disturbance of taste and tactile sensation have been reported previously in patients affected with Parkinson disease [23] and stroke [24], as well as in patients with head and neck cancer post-reconstruction $[25,26]$. Impairment of the sensory-cortical-motor feedback loops affects proper bolus formation and interrupts sequential swallowing response in the pharyngeal phase. Fortunately, sensory deficit after endotracheal extubation has been demonstrated to improve 14 days post-extubation [6]. However, there has been no evidence supporting improvement in tongue somatosensory function with exercise.

Tongue weakness and somatosensory disturbance are among the factors responsible for the development of dysphagia in patients under ventilator care. Given that these two factors might contribute to swallowing difficulty after prolonged endotracheal intubation, patients require intervention for improving tongue motion, strength, range of motion, and coordination. Further studies are required to examine whether oral motor exercises can help reduce pulmonary complications, morbidity, hospital costs, and duration of hospitalization in patients with oropharyngeal sensory-motor disturbances.

The present study has a few limitations. First, we were unable to evaluate explanatory variables because of the small sample size. Second, given the cross-sectional nature of the present study, we were unable to clarify causal relationships among the variables. Further longitudinal studies are required to achieve this objective. Third, the study subjects included patients with pneumonia, so we could not fully exclude the possibility of aspiration due to previous dysphagia. Further studies need to be performed excluding patients with pneumonia. Finally, we did not collect data regarding symptom presentation for sarcopenia and laryngeal dysmotility, which might influence swallowing difficulty.

In conclusion, objective bedside evaluation of tongue function is necessary in patients after extubation. It might aid in the early detection of PED and help minimize the risk of aspiration pneumonia.

\section{CONFLICT OF INTEREST}

No potential conflict of interest relevant to this article was reported.

\section{REFERENCES}

1. Skoretz SA, Flowers HL, Martino R. The incidence of dysphagia following endotracheal intubation: a systematic review. Chest 2010;137:665-73.

2. Kim MJ, Park YH, Park YS, Song YH. Associations between prolonged intubation and developing postextubation dysphagia and aspiration pneumonia in non-neurologic critically ill patients. Ann Rehabil Med 2015;39:763-71.

3. Cerenko D, McConnel FM, Jackson RT. Quantitative assessment of pharyngeal bolus driving forces. Otolaryngol Head Neck Surg 1989;100:57-63.

4. Robbins J, Gangnon RE, Theis SM, Kays SA, Hewitt $\mathrm{AL}$, Hind JA. The effects of lingual exercise on swallowing in older adults. J Am Geriatr Soc 2005;53:14839.

5. Maeda K, Akagi J. Decreased tongue pressure is associated with sarcopenia and sarcopenic dysphagia in the elderly. Dysphagia 2015;30:80-7.

6. Su H, Hsiao TY, Ku SC, Wang TG, Lee JJ, Tzeng WC, et al. Tongue weakness and somatosensory disturbance following oral endotracheal extubation. Dysphagia 2015;30:188-95.

7. Lee JH, Kim HS, Yun DH, Chon J, Han YJ, Yoo SD, et al. The relationship between tongue pressure and oral dysphagia in stroke patients. Ann Rehabil Med 2016; 40:620-8.

8. Scheel R, Pisegna JM, McNally E, Noordzij JP, Langmore SE. Endoscopic assessment of swallowing after prolonged intubation in the ICU setting. Ann Otol Rhinol Laryngol 2016;125:43-52.

9. Kim J, Oh BM, Kim JY, Lee GJ, Lee SA, Han TR. Validation of the videofluoroscopic dysphagia scale in various etiologies. Dysphagia 2014;29:438-43.

10. Skoretz SA, Yau TM, Ivanov J, Granton JT, Martino R. Dysphagia and associated risk factors following extubation in cardiovascular surgical patients. Dysphagia 2014;29:647-54.

11. Barker J, Martino R, Reichardt B, Hickey EJ, RalphEdwards A. Incidence and impact of dysphagia in 
patients receiving prolonged endotracheal intubation after cardiac surgery. Can J Surg 2009;52:119-24.

12. Ferraris VA, Ferraris SP, Moritz DM, Welch S. Oropharyngeal dysphagia after cardiac operations. Ann Thorac Surg 2001;71:1792-5.

13. Keeling WB, Lewis V, Blazick E, Maxey TS, Garrett JR, Sommers KE. Routine evaluation for aspiration after thoracotomy for pulmonary resection. Ann Thorac Surg 2007;83:193-6.

14. Adams V, Mathisen B, Baines S, Lazarus C, Callister R. A systematic review and meta-analysis of measurements of tongue and hand strength and endurance using the Iowa Oral Performance Instrument (IOPI). Dysphagia 2013;28:350-69.

15. Youmans SR, Stierwalt JA. Measures of tongue function related to normal swallowing. Dysphagia 2006;21: 102-11.

16. Robbins J, Levine R, Wood J, Roecker EB, Luschei E. Age effects on lingual pressure generation as a risk factor for dysphagia. J Gerontol A Biol Sci Med Sci 1995; 50:M257-62.

17. Clark HM, Solomon NP. Age and sex differences in orofacial strength. Dysphagia 2012;27:2-9.

18. Murray KA, Larson CR, Logemann JA. Electromyographic response of the labial muscles during normal liquid swallows using a spoon, a straw, and a cup. Dysphagia 1998;13:160-6.

19. Steele CM, Miller AJ. Sensory input pathways and mechanisms in swallowing: a review. Dysphagia 2010; 25:323-33.

20. Dong H, Loomis CW, Bieger D. Vagal afferent input determines the volume dependence of rat esophageal motility patterns. Am J Physiol Gastrointest Liver Physiol 2001;281:G44-53.

21. Lowell SY, Poletto CJ, Knorr-Chung BR, Reynolds RC, Simonyan K, Ludlow CL. Sensory stimulation activates both motor and sensory components of the swallowing system. Neuroimage 2008;42:285-95.

22. Boliek CA, Rieger JM, Li SY, Mohamed Z, Kickham J, Amundsen K. Establishing a reliable protocol to measure tongue sensation. J Oral Rehabil 2007;34:433-41.

23. Bakke M, Larsen SL, Lautrup C, Karlsborg M. Orofacial function and oral health in patients with Parkinson's disease. Eur J Oral Sci 2011;119:27-32.

24. Pow EH, Leung KC, McMillan AS, Wong MC, Li LS, Ho SL. Oral stereognosis in stroke and Parkinson's disease: a comparison of partially dentate and edentulous individuals. Clin Oral Investig 2001;5:112-7.

25. Vriens JP, Acosta R, Soutar DS, Webster MH. Recovery of sensation in the radial forearm free flap in oral reconstruction. Plast Reconstr Surg 1996;98:649-56.

26. Kuriakose MA, Loree TR, Spies A, Meyers S, Hicks WL Jr. Sensate radial forearm free flaps in tongue reconstruction. Arch Otolaryngol Head Neck Surg 2001;127: 1463-6. 